\title{
Evidence-Based Psychosocial Practices and Recovery from Schizophrenia
}

\author{
Glenn D. Shean
}

\begin{abstract}
Pessimistic views about the course and outcome of schizophrenia have been replaced by a more hopeful perspective that emphasizes on providing opportunities for recovery. Recovery, from a provider perspective, means that priority is placed on providing access to treatments and community services that have been proven effective in both decreasing symptoms and assisting individuals to lead maximally productive and personally meaningful lives. In 2004, the Schizophrenia Patient Outcomes Research Team (PORT) published a consensus list of evidence-based practices (EBPs) that includes six psychosocial treatments. These psychosocial interventions in combination with access to pharmacotherapy are important components of comprehensive treatment programs for the seriously mentally ill. This paper summarizes and updates the research basis for the PORT psychosocial EBPs and discusses several additional issues and research topics to be considered in the future.
\end{abstract}

Schizophrenia is a multifaceted disorder in which biological, psychological, and socio-cultural factors interact synergistically during all phases. Despite early pessimism about prospects for recovery, a growing body of evidence indicates that many individuals diagnosed with schizophrenia are capable of establishing meaningful lives and achieving good outcome (Harding, Brooks, Ashikaga, Strauss, \& Breier, 2005; Hopper, Harrison, \& Wanderling, 2007; Siegel, Wanderling, Lin, \& Baker, 2007). This evidence suggests that practitioners must rebalance the traditional clinical focus on symptoms and deficits with increased emphasis on the provision of comprehensive evidence-based services that enhance opportunities for recovery. This rebalancing should include provision of services that help build competencies, as well as opportunities for experiences that foster a viable sense of individuality, self-integrity, and productive involvement in society. When treatment with psychotropic medications is combined with access to adequately funded and administered evidence-based psychosocial programs, there are solid reasons to expect improved rates of recovery (DeSisto, Harding, \& McCormick, 1995).

The concept of recovery can be thought of as a multifaceted "open system" in which the domains of symptoms, social performance, and community functioning are relatively autonomous and require individually targeted treatments and interventions (Bellack, 2006; Spaulding, Sullivan \& Poland, 2003). As process, recovery includes those experiences and processes that foster healing both physically and emotionally, plus those that help foster positive changes in attitudes, feelings, perceptions, beliefs, goals, and roles in life, and that

Glenn D. Shean, PhD, is affiliated with the Psychology Department at the College of William and Mary in Williamsburg, Virginia. Address correspondence to him there at P.O. Box 8795. E-mail: gdshea@wm.edu. 
are associated with increased involvement in a process of self-renewal, independence, and responsibility (Liberman \& Kopelowicz, 2005; Loveland, Weaver-Randall, \& Corrigan, 2005). The process of recovery is favorably influenced by access to comprehensive and continuous evidence-based practices as well as personal and social factors (Kopelowicz \& Liberman, 2005). Treatments that are effective in reducing symptoms, improving social skills and relationships with family and others, and that help people become engaged in work and community life are effective ways to foster the processes of recovery (Harding, Brooks, Ashikaga, Strauss, \& Brier, 2005; Jenkins, 2005). As outcome, recovery can be defined as evidence of symptom remission; involvement in work or school; independent living without close supervision by caregivers; no full dependence on financial support from disability insurance; and having friends with whom activities are shared on a regular basis for at least two continuous years (Anthony, 2000; Liberman, Kopelowicz, Ventura, \& Gutkind, 2005). Recovery is distinct from "cure" in that it means that individuals diagnosed with schizophrenia can live reasonably normal lives even though they may be vulnerable to relapse and continue indefinitely to participate in comprehensive but flexible levels of services (Liberman \& Kopelowicz, 2005).

Beginning in 1992, the Agency for Health Care Policy and Research and the National Institute of Mental Health funded the Schizophrenia Patient Outcomes Research Team (PORT) to develop and disseminate recommendations for the treatment of schizophrenia based on existing scientific evidence. After exhaustive reviews of the literature, these treatment recommendations were published (Lehman \& Steinwach, 1998). The PORT treatment recommendations provided a basis for moving toward evidence-based practice for schizophrenia and identified the strengths and limitations of the current knowledge base. In 2004 The President's New Freedom Commission on Mental Health, influenced by the PORT report, stressed the importance of evidence-based practice and incorporated the values of the recovery movement: "We envision a future when everyone with a mental illness will recover, a future when mental illnesses can be prevented or cured ... and a future when everyone with a mental illness at any stage of life has access to effective treatment and supports--essential for living, working, learning, and participating fully in the community." The commission also emphasized that the nation must have a more effective system to identify, disseminate, and apply evidencebased practices (EBPs) to mental health care (President's New Freedom Commission on Mental Health, 2004, Executive summary p. 1). In 2004, the PORT published an updated consensus list of twenty EBPs, fourteen that refer to pharmacotherapy and six that describe psychosocial EBPs (Lehman, Kreyenbuhl, Buchanan, Dickerson, \& Goldberg, 2004). Surveys once again indicated that few patients diagnosed with schizophrenia were receiving even a modicum of EBPs (Lehman \& Steinwach, 2003). This paper summarizes and updates the evidence in support of the psychosocial EBPs identified by the PORT commission.

\section{Family Interventions}

The development of family psychoeducational (FE) therapy was inspired in part by research on the effects of family expressed emotion (EE) on re-hospitalization. EE research demonstrated that the course of schizophrenia for individuals who return to live at home or have frequent contact with family depends to a significant extent on how family members interact and deal with the patient during and after an initial episode of psychosis. Families in which members fail to understand the disorder often become critical, angry and accusatory, or over-involved with the former patient can significantly increase the likelihood of relapse and early return to hospital (Butzlaff \& Hooley, 1998). Elements of FE are designed to counteract the problems associated with high levels of family EE. FE therapies typically include: 
providing information about the disorder and its treatment; providing access to crisis intervention; providing emotional support; and teaching strategies for coping with symptoms and related problems along with ongoing support and access to clinical services. Topics for educational sessions may include problem-solving, coping and communication skills development, and crisis management. FE therapists strive to increase family members' understanding of the disorder and the patient's actions and needs in a manner that does not increase stigmatization, as well as to enhance the active social networks of family members. The goals of FE in brief are to increase understanding of the disorder, reduce $\mathrm{EE}$, reduce feelings of isolation, stress, and burden of family members, foster development of coping skills, and develop an ongoing collaborative relationship between family and clinicians. Prominent examples of empirically validated $\mathrm{FE}$ interventions include Behavioral Family Management (Falloon, Boyd, \& McGill, 1984), Family Psychoeducation (Anderson, Reiss, \& Hogarty, 1986), and Multifamily groups (McFarlane, 2002).

FE therapy has been demonstrated to reduce rates of hospital readmission, feelings of family burden, interpersonal conflict, and resentment, and improve patient-family relationships (Bebbington, Kuipers, \& Garety, 2002; Magliano, Fiorillo, \& Nakabgibem, 2006). Meta-analyses indicate that FE improves medication treatment adherence (Piling, Bebbington, Kuipers, Garety, Geddes, \& Martindale, 2002a, b), reduces frequency of relapse and number and duration of rehospitalizations (Pfammatter, Junghan, \& Brenner, 2006), and improves social functioning (Chien, Chan, \& Morrissey, 2005; Li \& Arthur, 2005; Magliano et al., 2006). Two-year relapse rates among participants who complete at least 9 months of FE are reduced on average by about $40 \%$ (Dyck, Hendryx, \& Short, 2002). FE services must be provided on a regular basis for a minimum of 9 months in order to measurably affect recidivism. Research is needed to determine how elements of FE result in changes related to reduced recidivism. It is not clear, for example, to what degree evidence of lower relapse rates with FE are the result of enhanced medication adherence, changes in the relatives' knowledge, lowered expectations and levels of expressed emotion, improved social support, reduced feelings of burden, or all of the above. An additional question to be addressed is the high attrition rates of key relatives reported in several studies of FE (Jeppesen, Petersen, \& Thorup, 2002). Strategies must be developed and tested to foster higher levels of ongoing participation in FE sessions, and booster sessions over extended intervals.

\section{Supported Employment (SE)}

Unemployment rates for people with mental disorders are high, with rates of up to 95\% for individuals diagnosed with severe mental disorders (Mueser, Salyers, \& Mueser, 2001). Surveys indicate that about $60 \%$ percent of people diagnosed with serious mental illnesses are capable of employment, and $70 \%$ say they would like to be working, but fewer than $15 \%$ were employed even temporarily, and less than $25 \%$ receive any form of vocational assistance (Leff $\&$ Warner, 2006). Several factors combine to make it difficult for individuals diagnosed with schizophrenia to find and maintain suitable employment. Intrinsic factors include increased vulnerability to stress, the episodic nature of the disorder, possible neurocognitive deficits, the presence of idiosyncratic behaviors and beliefs, social anxieties, low selfefficacy beliefs, and lack of vocational and social skills. Extrinsic factors include stigma on the part of potential employers, hiring practices that automatically eliminate applicants with spotty employment histories, government disability programs that discourage employment, and lack of access to appropriate SE services (Gold \& Waghorn, 2007). It is estimated that about 50-60 percent of the seriously mentally ill population are capable competitive employment if placed in appropriate SE programs (Bond, 2001). When SE services are combined with clinical and vocational services to establish competitive 
employment, outcome data indicates that more participants are likely to be competitively employed, to work 40 hours or more in a given month, and to earn significantly more money than those receiving traditional vocational services (Cook, Leff, Blyler, Gold, Goldberg, \& Mueser, 2005).

Supported employment services emphasize job search based on patient preference as well as continuing support to patient and employer from an employment specialist working as an integral member of the mental health service treatment and planning team. SE programs typically include: (1) integration of clinical and employment services; (2) provision of ongoing job support as needed; (3) development of job opportunities consonant with participants' abilities and preferences; and (4) provision of opportunities for an array of placements into permanent competitive employment (Mueser \& Bond, 2002). Randomized clinical trials indicate that rates for competitive employment on the open job market for patients using SE services more than double when compared to traditional services, and that well-designed and administered SE programs are cost effective (Bond, Salyers, Dincin, Becker, \& Fraser, 2007; Cook, et al., 2005; Latimer, Bush, Becker, Drake, \& Bond, 2004; Lehman, Goldberg, \& Dixon, 2002). A randomized controlled trial of SE conducted in six European centers reached similar conclusions, with the average rate of obtaining competitive employment for people with severe mental illness who were motivated to work double that of those provided with the usual high quality vocational rehabilitation (Burns, Catty, Becker, Drake, \& Fioritti, 2007). SE services are most effective when combined with additional services including access to medication and an array of psychosocial therapies (Lehman et al., 2004). Several programs have employed motivational strategies to help engage participants in the early stages of commitment to seeking employment, social skills training (Larson, Barr, \& Corrigan, 2007), and cognitive rehabilitation services for those with cognitive impairments (McGurk, Mueser, Feldman, Wolfe, \& Pascaris, 2007). Results indicate that SE participants receiving combined CR and SE services had better em- ployment outcomes over long-term follow-up than those receiving SE services alone (Bell, Greig, Zito, \& Wexler, 2007; McGurk et al., 2007).

Work is correlated with higher selfesteem, fewer hospital admissions, reduced health care costs, reduced positive and negative symptoms, enhanced social functioning, and improved quality of life (Bond, 2001; Cook et al., 2005). When individuals are employed, self-esteem increases, participation in social relationships is normalized, and overall functioning improves (Bengtsson-Tops \& Hansson, 2001; Bond, Resnick, \& Drake, 2001; Riches, \& Green, 2003). SE services are an important part of any recovery-oriented treatment program; however, it is important to recognize that participants may not achieve full-time employment. Of the approximately one-half of all individuals diagnosed with schizophrenia who enter SE services, only about 30 percent may transition to active phase of treatment, about 60 percent are likely to be placed in competitive employment, most work less than 40 hours a week, and monthly earnings are well below subsistence levels (Cook et al., 2005). Furthermore, the number of individuals working tends to gradually decrease over 2-year follow-up (McGurk, et al., 2007). Bond and Drake (2008) reviewed the literature on competitive employment and concluded that while the core principles of SE are reasonably well established, aspects such as job development and job support strategies need further research to enhance overall effectiveness. Research on implementation of SE programs is even more critical, since few organizations have solved the problems of adequate financing, organization, capacity integration, education, training, supervision, and fidelity needed to facilitate access to SE services for all who could benefit (Bond \& Drake, 2008).

\section{Assertive Community Treatment}

Assertive Community Treatment (ACT) is designed to actively follow people released from hospital into the community and to provide them with proactive commu- 
nity support at every step in the transition and adjustment process. ACT is not a clinical intervention; rather it is a way or organizing services to provide the help that is essential to effectively integrate certain individuals with severe mental illness into life in the community. ACT programs are not appropriate for everyone, and they are generally most effective with individuals at high risk for repeated hospitalizations, including medication-resistant and previously homeless individuals. ACT has not been found to afford a significant benefit for dual disorders (co-occurring psychosis and substance abuse) when compared with the usual integrated services for both disorders (Essock, Mueser, Drake, Covell, McHugo, \& Frisman, 2006). In ACT programs, staff will initiate contacts and follow up with participants as soon as they are released from the hospital. ACT programs are intended to accomplish coordination, integration, and continuity of services among providers over an extended period of time. Key elements of successful ACT programs include an integrated multidisciplinary team, team autonomy, a shared caseload among team members, high frequency of patient contact, 24/7 staff availability, patient-tostaff ratios of no more than $8-12$ patients per worker, and proactive outreach to patients in the community. ACT services can be effectively integrated with other psychosocial treatments such as SE (Jeppesen, Petersen, \& Thorup, 2002), FE (McFarlane \& Deakins, 2000), and skills training (Kurtz \& Mueser, 2008) to provide broad-based community services to foster the process of recovery. Successful ACT programs are effective in promoting client choice, a recovery perspective, and meaningful community integration (DeLuca, Moser, \& Bond, 2008). Staff must be particularly sensitive to the promotion of the processes of recovery given the intensive, assertive nature of many ACT services.

Studies in the United States, Australia, and Sweden have demonstrated the effectiveness of ACT in length of hospitalizations, reducing bed usage, and symptom severity; decreasing capitated costs; and improving living conditions of patients (Latimer, 2006; Rosenheck \& Dennis, 2001; Test \& Stein, 1980). The ACT framework is particularly well suited to be combined with implementation of other psychosocial EBPs, such as supported employment, family psychoeducation, and skills training to foster the recovery process (DeLuca, Moser, \& Bond, 2008).

\section{Skills Training}

Social skills training involves a range of training strategies and topics that typically include goal setting, behaviorally based instruction, role modeling, behavioral rehearsal, corrective feedback, positive reinforcement, and homework to foster generalization of skills (Kopelowicz, Kreyenbuhl, \& Buchanan, 2006). Skills group sessions may focus on: (1) basic conversation and communication skills and expressiveness; (2) symptom management; (e) assertiveness: (4) medication adherence and negotiation skills with service providers; (5) developing friendships; (6) job finding and communication; and (7) problem solving with peers, coworkers, and roommates. Skills training is ideally implemented in the context of a multi-element treatment program that may include medication management, intensive case management, crisis services, family psychoeducation, SE job coaching and training, access to supported housing, and other services. Research indicates that social skills training results in positive benefits to participants (Piling et al., 2002b), that the benefits of skills training generalizes from hospital or clinic-based training settings to the everyday lives of patients living in the community (Liberman \& Kopelowicz, 2002), and has a positive impact on social and community outcomes (Pfamatter et al., 2006). Pfammatter, Junghan, and Brenner (2006) conducted a meta-analysis of randomized controlled trial studies and concluded that results indicated large effects of social skills training on skills development, with smaller effects on assertiveness, social functioning, and general psychopathology. Kurtz and Mueser (2008) 
completed a recent meta-analysis of 22 studies including 1,521 participants in randomized, controlled trials of social skills training. They concluded that results indicated a large effect size for content mastery exams, moderate effects for performance-based measures of social and daily living skills, community functioning, and negative symptoms, and small effect sizes for other symptoms and relapse rates. Kurtz and Mueser (2008) also noted that schizophrenia is not a homogenous disorder and skills training may not be appropriate for all individuals who meet diagnostic criteria. The authors suggested several avenues for further study. First, it is not clear to what degree individuals with better premorbid skill levels and later onset of illness benefit from standard social skills training, as compared to those with earlier onset and poor premorbid adjustment. Second, more research is needed on the impact of the presence of neurocognitive deficits in a large proportion of individuals diagnosed with schizophrenia on social skills training. Evidence suggests that treatments that incorporate behavioral treatments of neurocognitive deficits with psychosocial therapies such as social skills training can effectively enhance prospects for recovery (McGurk, Twamley, Sitzer, McHugo, \& Mueser, 2007). In addition to research on the effectiveness of combining different psychosocial EBPs, there is a need for more long-term follow-up studies of the effects of skills training, skills training in combination with efforts to remediate specific cognitive deficits, and the potential benefits of booster sessions

\section{Cognitive Behaviorally Oriented Psychotherapy}

Cognitive behaviorally oriented psychotherapy (CBT) attempts to reduce certain symptoms and enhance functioning by entering into a dialogue that provides rational alternative perspectives to the patient's experiences, with the goal of helping him or her to better understand and cope with issues and experiences that are especially problematic for the individual. CBT goals and strategies include helping individuals to recognize delusional thoughts, early signs of relapse, and learning stress reduction tools and coping strategies (Bellack, 2004). The basic elements and process of CBT include: development of a shared understanding of the illness between patient and therapist, mutual identification of target symptoms, and implementation of specific cognitive and behavioral strategies to cope with these symptoms. CBT focuses on encouraging individuals to re-appraise delusional beliefs in order to reduce distress, reduce negative schemas, more effectively manage stressful environments, change reasoning biases by the application of therapy-assisted disconfirmation strategies, and detailed consideration of the full range of evidence. CBT sessions are conducted weekly or biweekly over a period of about nine months. CBT can be effective in reducing overall symptom ratings for acute patients (Gumley, O'Grady, \& McNay, 2003; Gumley, Karatzias, \& Power, 2006; Haddock \& Lewis, 2005; Lewis, Tarrier, \& Haddock, 2002; Rector, Seeman, \& Segal, 2003; Turkington, Kingdon, \& Turner, 2002). Studies also indicate that CBT for early schizophrenia results in transient but faster improvements in positive and negative symptoms and delusional beliefs (Gumley et al., 2006). Meta-analysis indicates that CBT results in declines in ratings of general psychopathology and positive symptoms (Pfammatter et al., 2006). Multielement psychosocial intervention programs for early psychosis that include CBT have improved social functioning, increased insight, decreased substance abuse and self-harm behaviors, improved medication adherence, reduced time spent in hospital, and higher levels of satisfaction with treatment (Kemp, Kirov, \& Everitt, 1998; Penn, Waldheter, \& Perkins, 2001).

The effects of CBT on ratings of social and occupational functioning (Bechdolf, Kohn, \& Knost, 2005; Temple \& Ho, 2005), as well as rehospitalization are equivocal (Gumley, Karatzias, \& Power, 2006; Startup, Jackson, \& Bendix, 
2004). CBT appears to be most effective early in the course of the disorder (Zimmerman, Favord, $\&$ Trieu, 2005) and may not be more effective than nonspecific counseling with other individuals diagnosed with schizophrenia (McIntosh, Conlon, \& Lawrie, 2006). Limitations of extant studies of CBT include: 1) the criterion for research participation included in many studies, that participants must be distressed by their delusions, and 2) high attrition rates (Drury, Birchwood, Cochrane, \& MacMillan, 1996). Research is needed to develop and evaluate modifications in CBT that can potentially increase its effectiveness with patients evidencing different phenotypic symptom patterns, its impact on social functioning, and to determine how CBT can be most effectively integrated with and augment other psychosocial interventions to foster recovery processes.

\section{Token Economy Interventions}

Token economies are structured programs based on the principles of contingent positive reinforcement for target behaviors based on individualized treatment plans, and the avoidance of punishing consequences. In these programs tokens or points are used to increase motivation by providing reinforcement for the performance of specified target behaviors; tokens may be exchanged at a later time for individually selected reinforcers. Several advantages accrue from the use of tokens to provide immediate reinforcement of prosocial skills, including opportunities to reinforce complex behavioral sequences in an incremental manner and the opportunity to maintain the reinforcing properties of tokens through access to an array of backup rewards (Corrigan \& Liberman, 1994). Token economies have been effective in increasing in-hospital adaptive behaviors of patients diagnosed with schizophrenia in hospital and residential treatment environments, particularly in cases where residents are socially withdrawn, unmotivated, and have difficulty performing routine activities of daily living (Dickerson, Tenhula \& Green-
Paden, 2005). Evidence indicates that when intensive behavioral treatment that includes token reinforcement is combined with appropriate pharmacotherapy, the number of patients considered to be treatment refractory is far lower than when medication alone or medication plus standard treatment are used (Silverstein, Hatashita-Wong, \& Bloch, 2002). Overall research indicates that the reward systems of many withdrawn "institutionalized" patients can be reactivated with consistent external cueing and opportunities for contingent reinforcement (Velligan, Kern, \& Gold, 2006). This effect is relevant to the rehabilitation of many long-term patients since the issues of withdrawal and lack of motivation are often central to rehabilitation (Koren, Seidman, \& Goldsmith, 2006). Research is needed to determine the specific benefits of token reinforcement programs for reliably identified sub-groups, when administered in combination with other pharmacological and psychosocial treatments such as social skills, SE, and cognitive rehabilitation.

\section{COGNITIVE REHABILITATION}

Cognitive processing deficits are present in many individuals diagnosed with schizophrenia before onset, remain after most symptoms have remitted, and are correlated with measures of community adjustment, social problem solving, and social skills learning (Green, 1996; Twamey, Jeste, \& Bellack, 2003). Cognitive deficits are resistant to the effects of medication, are persistent, and are among the strongest predictors of a variety of domains of functional behaviors (Green, Kern, Braff, \& Mintz, J., 2001; Milev, Ho, Arndt, \& Andreasen, 2005; Rempfer, Manera, Brown, \& Cromwell, 2003; White, Friedman, \& Bowie, 2006). The 2004 PORT recommendations did not address research cognitive rehabilitation (CR); however, the PORT review is reviewing research on this topic. CR can be characterized as provid- 
ing repetitive practice along with compensatory cognitive-skill acquisition focused on elementary cognitive and more complex social-cognitive measures (Heydebrand, 2007; Kurtz \& Nichols, 2007; Spaulding \& Poland, 2001). Research reviews and metaanalyses of randomized controlled studies indicate that CR therapy is associated with significant improvements on measures of working memory, executive function and facial affect perception, and has small effects on some symptoms (Hogarty, Flesher, Ulrich, Carter, \& Greenwald, 2004; Kurtz \& Nichols, 2007; McGurk, Twamley, Sitzer, $\mathrm{McHu}-$ go, \& Mueser, 2007). Evidence also indicates that when combined with vocational rehabilitation and SE services, CR produces more superior outcomes than when these interventions are provided singly in the absence of CR (Greig, Zito, Wexler, Fiszdon, \& Bell, 2007; Heydebrand, 2007; Kurtz \& Nichols, 2007; McGurk, Mueser, Feldman, Wolfe, \& Pascaris, 2007). CR seems best suited to be integrated with other psychosocial rehabilitation programs. Consequently, research is needed on the most effective means of integrating cognitive rehabilitation with other psychosocial therapies (Heydebrand, 2007; Kurtz \& Nichols, 2007; McGurk, Mueser, Feldman, Wolfe, \& Pascaris, 2007).

\section{RELATED CONCERNS THAT AFFECT RECOVERY}

There are many issues, in addition to access to comprehensive EPB-based treatment programs that can impact the process of recovery (Warner, 2004). Prominent concerns in the author's view include the impact of stigma, the value of access to consumerprovided services, provision of improved incentives to work, and the quality of implementation of EBP-based treatment programs. Stigma can have an important impact on personal, social, and economic resources and opportunities, and contribute to the negative transformation of self-identities that can interfere with recovery (Phelan, Link, Stueve, \& Pescosolido, 2000; Watson \& Corrigan, 2005). Improved efforts to change self and public attitudes toward mental disorders can have an important impact on opportunities for recovery. Second, the potential benefits of consumer involvement in the planning and provision of services also merit further study. Mutual-support groups can facilitate the process of recovery by helping individuals view themselves and their problems as less deviant and alter understanding of self (DenBoer, Wiersma, \& Van Den Bosch, 2004; Rummel, Hansen, \& Helbig, 2005; Yanos, Primavera, \& Knight, 2001; Young, Green, \& Estroff, 2008). Public policies can also impact motivation and willingness to participate in recovery-oriented programs, such as supported employment services. Today in the US the majority of individuals diagnosed with schizophrenia subsist on social security disability pensions (Polak \& Warner, 1996), and only one half of $1 \%$ ever remove themselves from entitlements (Kurtz \& Nichols, 2007). Disincentives in current disability pension regulations are barriers to employment by beneficiaries (U.S. General Accounting Office, 1996). Research is needed on the effects of policies that provide temporary or permanent wage subsidies and innovations that increase the amounts persons on disability pensions can earn without penalty. Finally, since there are wide variations in the quality and fidelity of implementation of programs in terms of leadership, staffing, policies, access to training and supervision, and mastery of the therapeutic principles and practices (Essock, Covell, \& Weissman, 2004; Moser, Deluca, \& Bond, 2004). Quality implementation is necessary to translate EBPs from clinical research facilities to everyday practice. Finally, there is no data base available today to allow assessment of how often or how well programs carry out basic program functions, there is consequently no 
way to measure progress. Research on the most effective means of dissemination and implementation of EBPs is critical, since few organizations have solved the problems of adequate financing, organization, capacity integration, education, training, supervision, and fidelity needed to facilitate access to all who could benefit (Bond \& Drake, 2008).

\section{CONCLUSION}

If we are to foster improved prospects for recovery for individuals diagnosed with schizophrenia, we must provide access to comprehensive programs that provide competent application and coordination of EBPs by compassionate clinicians. The advantages of combining the PORT-recommended EBPs from a practitioner's perspective include the prescribing psychiatrists' benefit in selecting type and dose of medication after receiving information on changes in symptoms, side effects, and cognitive and social functioning from staff conducting psychosocial therapies, as well as the latter receiving ongoing information from the psychiatrist regarding changes in medication and symptoms as therapy progresses. Research is needed now to: (1) determine how to develop and evaluate multi-element programs that integrate various psychosocial EBPs into packages that can be offered to the recovering individual in rehabilitation planning sessions; (2) determine the interaction of different psychosocial therapies with individual differences; (3) carry out long-term studies on the effects of psychosocial therapies using operationalized measures of recovery; (4) study the role of work in fostering recovery; and (5) develop and use more valid measures of interpersonal and social functioning to evaluate the effects of therapies (Liberman, Kopelowicz, Ventura, \& Gutkind, 2005; Silverstein, Spaulding, $\&$ Menditto, 2006).

\section{REFERENCES}

Anderson, C.M., Reiss, D.J., \& Hogarty, G.E. (1986). Schizophrenia and the Family. New York: Guilford.

Anthony, W. (2000). A recovery-oriented service system: Setting some system level standards. Psychiatric Rehabilitation Journal, 24, 159-175.

Bebbington, P., Kuipers, E., \& Garety, P. (2002). Long-term community care through an assertive continuous treatment team. In C.A. Tammaniga and S. Schulz (Eds.), Advances in Neuropsychiatry and Psychopharmacology Vol. I: Schizophrenia Research (pp. 239-246). New York: Raven.

Bechdolf, A., Kohn, D., \& Knost, B. (2005). A randomized comparison of group cognitivebehavioral therapy and group psychoeducation in acute patients with schizophrenia: Outcome at 24 months. Acta Psychiatrica Scandinavica, 112, 173-179.
Bell, M.D., Greig, T.C., Zito, W., \& Wexler, W. (2007). An RCT of neurocognitive enhancement therapy with supported employment: Employment outcomes at 24 months. Schizophrenia Bulletin, 33, 420-421.

Bellack, A.S. (2004). Skills training for people with severe mental illness. Psychiatric Rehabilitation Journal, 27, 375-391.

Bellack, A.S. (2006). Scientific and consumer models of recovery in schizophrenia: Concordance, contrasts and implications. Schizophrenia Bulletin, 32, 432-442.

Bengtsson-Tops, A., \& Hansson, L. (2001). Quantitative and qualitative aspects of the social network in schizophrenic patients living in the community relationship to sociodemographic characteristics and clinical factors and subjective quality of life. International Journal of Social Psychiatry, 47, 67-77. 
Bond, G.R. (2001). Implementing supported employment as an evidence-based practice. Psychiatric Services, 52, 313-322.

Bond, G.R., Resnick, S.G., \& Drake, R.E. (2001). Does competitive employment improve non-vocational outcomes for people with severe mental illness? Journal of Consulting and Clinical Psychology, 69, 489-501.

Bond, G.R., Salyers, M.P., Dincin, J., Becker, D.R., \& Fraser, V.V. (2007). A randomized controlled trial comparing two vocational models for persons with severe mental illness. Journal of Consulting and Clinical Psychology, 75, 968-982.

Bond, G.R., \& Drake, R.E. (2008). Predictors of competitive employment among patients with schizophrenia. Current Opinion in Psychiatry, 21, 362-369.

Burns, T., Catty, J., Becker, T., Drake, R., \& Fioritti, A. (2007). The effectiveness of supported employment for people with severe mental illness: A randomized controlled trial. Lancet, 370, 1146-1152.

Butzlaff, R.I., \& Hooley, J.M. (1998). Expressed emotion and psychiatric relapse. Archives of General Psychiatry, 55, 547-552.

Chien, W.T., Chan, S., \& Morrissey, J. (2005). Effectiveness of a mutual support group for families of patients with schizophrenia. Journal of Advanced Nursing, 51, 595-605.

Cook, J.A., Leff, H.S., and Blyler, C.R., Gold, P.B., Goldberg, R.W., \& Mueser, K.T. (2005). Results of a multi-site randomized trial of supported employment interventions for individuals with severe mental illness. Archives of General Psychiatry, 62, 505-512.

Corrigan, P.W., \& Liberman, R.P. (1994). Overview of behavior therapy in psychiatric hospitals. In P.W. Corrigan and R.P. Liberman (Eds.), Behavior Therapy in Psychiatric Hospitals (pp. 1-38). New York: Springer.

DeLuca, N.L., Moser, L.L., \& Bond, G.R. (2008). Assertive community treatment. In K.T. Mueser \& D.V. Jeste (Eds.), Clinical Handbook of Schizophrenia (pp. 329-338). New York: Guilford.
DenBoer, P., Wiersma, D., \& Van Den Bosch, R. (2004). Why is self-help neglected in the treatment of emotional disorders? A meta-analysis. Psychological Medicine, 34, 959-971.

DeSisto, M.J., Harding, C.M., \& McCormick, R.V. (1995). The Maine and Vermont three-decade studies of serious mental illness. II. Longitudinal course comparisons. British Journal of Psychiatry, 167, 338-342.

Dickerson, F.B., Tenhula, W.N., \& GreenPaden, L.D. (2005). The token economy for schizophrenia: A review of the literature and recommendations for future research. Schizophrenia Research, 75, 2-3.

Drury, V., Birchwood, M., Cochrane, R., \& MacMillan, F. (1996). Cognitive therapy and recovery from acute psychosis: A controlled trial. II. Impact on recovery time. British Journal of Psychiatry, 169, 593-601.

Dyck, D.G., Hendryx, M.S., \& Short, R.A. (2002). Service use among patients with

schizophrenia in psychoeducational multiplefamily group treatment. Psychiatric Services, 53, 749-754.

Essock, S.M., Covell, N.H., \& Weissman, E.M. (2004). Inside the black box: The importance of monitoring treatment implementation. Schizophrenia Bulletin, 30, 613-615.

Essock, S.M., Mueser, K.T., Drake, R.E., Covell, N.H., McHugo, G.J., \& Frisman, L.K.

(2006). Comparison of ACT and standard case management for delivering integrated

treatment for co-occurring disorders. Psychiatric Services, 57, 185-196.

Falloon, I.R.H., Boyd, J.I., \& McGill, C.W. (1984). Family Care of Schizophrenia: A Problem-Solving Approach to the Treatment of Mental Illness. New York: Guilford.

Gold, P.B., \& Waghorn, G. (2007). Supported employment for people with severe mental illness. Lancet, 370, 1108-1109.

Green, M.F. (1996). What are the functional consequences of neurocognitive deficits in 
schizophrenia? American Journal of Psychiatry, 153, 321-330.

Green, M.F., Kern, R.S., Braff, D.L., \& Mintz, J. (2001). Neurocognitive deficits and functional outcome in schizophrenia: Are we measuring the "right stuff?" Schizophrenia Bulletin, 26, 119-136.

Greig, T.C., Zito, W., Wexler, B.E., Fiszdon, J., \& Bell, M.D. (2007). Improved cognitive function in schizophrenia after one year of cognitive training and vocational services. Schizophrenia Research, 96, 156-161.

Gumley, A., O'Grady, M., \& McNay, L. (2003). Results of a 12-month randomized controlled trial of cognitive behavioral therapy. Psychological Medicine, 33, 419-433.

Gumley, A., Karatzias, A., \& Power, K. (2006). Early intervention for relapse in schizophrenia: Impact of cognitive behavioral therapy on negative beliefs about psychosis and selfesteem. British Journal of Clinical Psychology, 45, 247-260.

Haddock, G., \& Lewis, S. (2005). Psychological interventions in early psychosis. Schizophrenia Bulletin, 31, 697-704.

Harding, C.S., Brooks, G.W., Ashikaga, T., Strauss, J.S., \& Breier, A. (2005). The Vermont longitudinal study of persons with severe mental illness II. Long-term outcome of subjects who retrospectively met DSM-III criteria for schizophrenia. In L. Davidson, C. Harding, \& L. Spanol (Eds.), Recovery from Severe Mental Illnesses: Research Evidence and Implications for Practice, Vol. 1. (pp. 180-200). Boston: Center for Psychiatric Rehabilitation.

Heydebrand, G. (2007). Issues in rehabilitation of cognitive deficits in schizophrenia: A critical review. Current Psychiatry Reviews, 3, 186-195.

Hogarty, G., \& Flesher, S. (1999). Practice principles of Cognitive Enhancement Therapy for schizophrenia. Schizophrenia Bulletin, 25, 693-708.

Hogarty, G.E., Flesher, S., Ulrich, R., Carter, M., \& Greenwald, D. (2004). Cognitive en- hancement therapy for schizophrenia. Archives of General Psychiatry, 61, 866-876.

Hopper, K., Harrison, G., \& Wanderling, J.A. (2007). An overview of course and outcome in ISoS. In K. Hopper, G. Harrison, J. Aleksandar, $\&$ N. Satorius (Eds.),

Recovery from Schizophrenia (pp. 23-38). Oxford: Oxford University Press.

Jenkins, J.H. (2005). The new paradigm of recovery from schizophrenia: Cultural conundrums of improvement without cure. Culture, Medicine and Psychiatry, 29, 379-413.

Jeppesen, P., Petersen, L., \& Thorup, A. (2002) Integrated treatment of first-episode psychosis: Effect of treatment on family burden. British Journal of Psychiatry, 187 (suppl.), s85-s90.

Kemp, R., Kirov, G., \& Everitt, B. (1998). Randomized controlled trial of compliance therapy: 18-month follow-up. British Journal of Psychiatry, 172, 413-419.

Kopelowicz, A., \& Liberman, R.P. (2005). Neurocognitive correlates of recovery from schizophrenia. Psychological Medicine, 35, 1165-1173.

Kopelowicz, A., Kreyenbuhl, J., \& Buchanan, R. (2006). Recent advances in social skills training for schizophrenia. Schizophrenia Bulletin, 32, s12-s23.

Koren, D., Seidman, L.J., \& Goldsmith, M. (2006). Real-world cognitive and metacognitive dysfunction in schizophrenia: A new approach for measuring (and remediating) more "right stuff." Schizophrenia Bulletin, 32, 310-326.

Kurtz, M.M., \& Nichols, M.C. (2007). Cognitive rehabilitation for schizophrenia: A review of recent advances. Current Psychiatry Reviews, 3, 213-221.

Kurtz, M.M., \& Mueser, K.T. (2008). A metaanalysis of controlled research on social skills training for schizophrenia. Journal of Consulting and Clinical Psychology, 76, 491-504.

Larson, J.E., Barr, L.K., \& Corrigan, P.W. (2007). Perspectives on benefits and costs of work from individuals with psychiatric dis- 
abilities. Journal of Vocational Rehabilitation, 26, 71-77.

Latimer, E.A., Bush, P.W., Becker, D.R., Drake, R.E., \& Bond, G.R. (2004). The cost of hifidelity supported employment programs for people with severe mental illness. Psychiatric Services, 55, 401-406.

Latimer, E. (2006) Economic considerations associated with assertive community treatment and supported employment for people with severe mental illness. Journal of Psychiatry and Neuroscience, 30, 355-359.

Leff, J., \& Warner, R. (2006). Social Inclusion of People with Mental Illness. Cambridge: Cambridge University Press.

Lehman, A.F., \& Steinwach, D.M. (1998). At issue: Translating research into practice: The schizophrenia patient outcomes research team (PORT) treatment recommendations. Schizophrenia Bulletin, 24, 1-10.

Lehman, A.F., Goldberg, R.W., \& Dixon, L.B. (2002). Improving employment outcomes for persons with severe mental illness. Archives of General Psychiatry, 59(2), 165-172.

Lehman, A.F., \& Steinwach, D.M. (2003). Evidence-based psychosocial treatment practices in schizophrenia: Lessons from the Patient Outcomes Research Team (PORT) project.

Journal of the American Academy of Psychoanalysis \& Dynamic Psychiatry, 31, 141-154. Lehman, A.F., Kreyenbuhl, J., Buchanan, R.W., Dickerson, F.B., \& Goldberg, R. (2004). The schizophrenia patient outcomes research team (PORT): Updated treatment recommendations 2003. Schizophrenia Bulletin, 30(2), 193-217.

Lewis, S., Tarrier, N., \& Haddock, G. (2002). Randomized controlled trial of cognitive-behavioral therapy in early schizophrenia: Acutephase outcomes. British Journal of Psychiatry, 24 (Suppl.), 91-97.

Li, Z., \& Arthur, D. (2005). Family education for people with schizophrenia in Beijing, China: Randomized controlled trial. British Journal of Psychiatry, 187, 339-345.
Liberman, R.P., \& Kopelowicz, A. (2002). Recovery from schizophrenia: A challenge for the 21st century. International Review of Psychiatry, 14, 245-255.

Liberman, R.P., \& Kopelowicz, A. (2005). Recovery from schizophrenia: A recoverybased definition. In R.O. Ralph \& P.W. Corrigan (Eds.), Recovery in Mental Illness (pp. 101-129). Washington, DC: American Psychological Association.

Liberman, R. P., Kopelowicz, A., Ventura, J., \& Gutkind. (2005). Operational criteria and factors related to recovery from schizophrenia. In L. Davidson, C. Harding, \& L. Spanol (Eds.), Recovery from Severe Mental Illnesses: Research Evidence and Implications for Practice, Vol. 1. (pp. 260-292). Boston: Center for Psychiatric Rehabilitation.

Loveland, D., Weaver-Randall, K., \& Corrigan, P.W. (2005). Research methods for exploring and assessing recovery. In R.O. Ralph \& P.W. Corrigan (Eds.), Recovery in Mental Illness (pp. 19-60). Washington, DC: American Psychological Association.

Magliano, L., Fiorillo, A., \& Nakabgibem, C. (2006). Family psychoeducational interventions for schizophrenia in routine settings: Impact on patients' clinical status and social functioning and on relatives' burden and resources. Epidemiological Psychiatry and Society, 15, 219-227.

McFarlane, W.R., \& Deakins, S.M. (2000). Family-aided assertive community treatment. In W.R. McFarlane (Ed.), Multifamily Groups in the Treatment of Severe Psychiatric Disorders (pp.175-197). New York: Guilford.

McFarlane, W.R. (2002). Multifamily Groups in the Treatment of Severe Psychiatric Disorders. New York: Guilford.

McGurk, S.R., Mueser, K.T., Feldman, K., Wolfe, R., \& Pascaris, A. (2007). Cognitive training for supported employment: 2-3 year outcomes of a randomized controlled trial. American Journal of Psychiatry, 164, 437-441.

McGurk, S.R., Twamley, E.W., Sitzer, D.I., McHugo, G.J., \& Mueser, K.T. (2007). A me- 
ta-analysis of cognitive remediation in schizophrenia. American Journal of Psychiatry, 164, 1791-1802.

McIntosh, A.M., Conlon, L., \& Lawrie, S.M. (2006). Compliance therapy for schizophrenia. Cochrane Database system Review, 3, CD003442.

Milev, P., Ho, B.C., Arndt, S., \& Andreasen, N. (2005). Predictive values of neurocognition and negative symptoms on functional outcome in schizophrenia: Longitudinal first-episode study with 7-year follow up. American Journal of Psychiatry, 162, 495-506.

Moser, I., Deluca, N., \& Bond, G., (2004). Implementing evidence-based psychosocial practices: Lessons learned from statewide implementation of two practices. CNS Spectrum, 9, 926-926.

Mueser, D.R., \& Bond, G.R. (2002). Supported Employment Implementation Resource Kit. Rockville, MD: Center for Mental Health Services, Substance Abuse and Mental Health Services Administration.

Mueser, K.T., Salyers, M.P., \& Mueser, P.R. (2001). A prospective analysis of work in schizophrenia. Schizophrenia Bulletin, 27, 281-296.

Penn, D.L., Waldheter, E.J., \& Perkins, D.O. (2001). Psychosocial treatment for first-episode psychosis: A research update. American Journal of Psychiatry, 162, 2220-2232.

Pfammatter, M., Junghan, U.M., \& Brenner, H.D. (2006). Efficacy of psychological therapy in schizophrenia: Conclusions from meta-analyses. Schizophrenia Bulletin, 32, Suppl. 1, s4-s68.

Phelan, J.C., Link, B.G., Stueve, A., \& Pescosolido, B. (2000). Public conceptions of mental illness in 1950 and 1996: What is mental illness and is it to be feared? Journal of Health and Social Behavior, 41, 188-207.

Piling, S., Bebbington P., Kuipers, E., Garety, P., Geddes, J., \& Martindale, B. (2002a). Psychological treatments in schizophrenia: I. Metaanalysis of family intervention and cognitive behavior therapy. Psychological Medicine, 32, 763-782.

Piling, S., Bebbington, P., Kuipers, E., Garety, P., Geddes, J., \& Martindale, B. (2002b). Psychological treatments in schizophrenia. II. Meta-analyses of randomized controlled trials of social skills training and cognitive remediation. Psychological Medicine, 32, 783-791.

Polak, P.R., \& Warner, R. (1996). The economic life of seriously mentally ill people in the community. Psychiatric Services, 47, 270-274.

President's New Freedom Commission on Mental Health. (2004). Achieving the promise: Transforming mental health care in America. Available at mentalhealthcommission.gov/reports.

Rector, N.A., Seeman, M.V., \& Segal, Z.V. (2003). Cognitive therapy for schizophrenia: A preliminary randomized controlled trial. Schizophrenia Research, 63, 1-11.

Rempfer, M.V., Manera, E.K., Brown, C.E., \& Cromwell, R. L. (2003). The relations between cognition and the independent living skill of shopping in people with schizophrenia. Psychiatry Research, 117, 103-112.

Riches, V.C., \& Green, V.A. (2003). Social integration in the workplace for people with disabilities: An Australian perspective. Journal of Vocational Rehabilitation, 19, 127-142.

Rosenheck, R., \& Dennis, D. (2001). Time-limited assertive community treatment for homeless persons with severe mental illness. Archives of General Psychiatry, 58, 1073-1080.

Rummel, C.B., Hansen, W.P., \& Helbig, A. (2005). Peer-to-peer psychoeducation in schizophrenia: A new approach. Journal of Clinical Psychiatry, 66, 1580-1585.

Siegel, C., Wanderling, J.A., Lin, S., \& Baker, S. (2007). Predictors of long-term course and outcome for the DOSMeD cohort. In K. Hopper, G. Harrison, A. Janca, \& N. Satorius (Eds.), Recovery from Schizophrenia (pp. 39-60). Oxford: Oxford University Press.

Silverstein, S.M., Hatashita-Wong, M., \& Bloch, A. (2002). A second chance for people 
with "treatment refractory" psychosis. Psychiatric Services, 53, 480.

Silverstein, S., Spaulding, W., \& Menditto, A. (2006). Schizophrenia. Ashland, OH: Hogrefe \& Huber.

Spaulding, W.D., \& Poland, J. (2001). Cognitive rehabilitation for schizophrenia: Enhancing social cognition by strengthening neurocognitive functioning. In P. Corrigan \& D. Penn (Eds.). Social Cognition and Schizophrenia. (pp. 217-247). Washington, DC: American Psychological Association.

Spaulding, W.D., Sullivan, M.E., \& Poland, J.S. (2003). Treatment and Rehabilitation of Severe Mental Illness. New York: Guilford.

Startup, M., Jackson, M.C., \& Bendix, S. (2004). North Wales randomized controlled trial of cognitive behavior therapy for acute schizophrenia spectrum disorders: Outcomes at 6 and 12 months. Psychological Medicine, $34,413-422$.

Temple, S., \& Ho, B.C. (2005). Cogntive therapy for persistent psychosis in schizophrenia: A case-controlled clinical trial. Schizophrenia Research, 74, 195-199.

Test, M.A., Stein, L.I. (1980). Alternative to mental hospital treatment. III. Social cost. Archives of General Psychiatry, 37, 409-412.

Turkington, D., Kingdon, D., \& Turner, T. (2002). Effectiveness of a brief cognitivebehavioral intervention in the treatment of schizophrenia. British Journal of Psychiatry, 180, 523-527.

Twamley, E.W., Jeste, D.V., \& Bellack, A.S. (2003). A review of cognitive training in schizophrenia. Schizophrenia Bulletin, 29, 359-382.

U.S. General Accounting Office. (1996). SSA Disability: Program Redesign Necessary to Encourage Return to Work: Report to the Chairman, Special Committee on Aging and the U.S. Senate (GAO/HEHS 96-62). Washington, DC: Author.
Velligan, D.I., Kern, R.S., \& Gold, J.M. (2006). Cognitive rehabilitation for schizophrenia and the putative role of motivation and expectancies. Schizophrenia Bulletin, 32, 474-485.

Warner, R. (2004). Recovery from Schizophrenia: Psychiatry and Political Economy (3rd ed.). New York: Brunner-Routledge.

Watson, A.C., \& Corrigan, P.W. (2005). Challenging public stigma: A targeted approach. In P.W. Corrigan (Ed.). On the Stigma of Mental Illness: Practical Strategies for Research and Social Change (pp. 281-296). Washington, DC: American Psychological Association.

White, L., Friedman, J.I., \& Bowie, C.R. (2006). Long-term outcomes in chronically hospitalized geriatric patients with schizophrenia: Retrospective comparison of first generation and second generation antipsychotics. Schizophrenia Research, 88, 127-134.

Wilken, J. P. (2007). Understanding recovery from psychosis: A growing body of knowledge. Tidsskrift for Norsk Psykilogforening, 44, 658-666.

Yanos, P.T., Primavera, L.H., \& Knight, E.L. (2001). Consumer-run service participation, recovery of social functioning, and the mediating role of psychological actors. Psychiatric Services, 52, 493-500.

Young, A.T., Green, C.A., \& Estroff, S.E. (2008). New endeavors, risk taking, and personal growth in the recovery process: Findings from the STARS study. Psychiatric Services, 59, 1430-1436.

Zimmerman, G., Favord, J., \& Trieu, V.H. (2005). The effect of cognitive behavioral treatment on the positive symptoms of schizophrenia spectrum disorders: A meta-analysis. Schizophrenia Research, 77, 1-9. 
Copyright of Psychiatry: Interpersonal \& Biological Processes is the property of Guilford Publications Inc. and its content may not be copied or emailed to multiple sites or posted to a listserv without the copyright holder's express written permission. However, users may print, download, or email articles for individual use. 